Supplement of

\title{
Effects of marine organic aerosols as sources of immersion-mode ice-nucleating particles on high-latitude mixed-phase clouds
}

Xi Zhao et al.

Correspondence to: Xiaohong Liu (xiaohong.liu@tamu.edu)

The copyright of individual parts of the supplement might differ from the CC BY 4.0 License. 

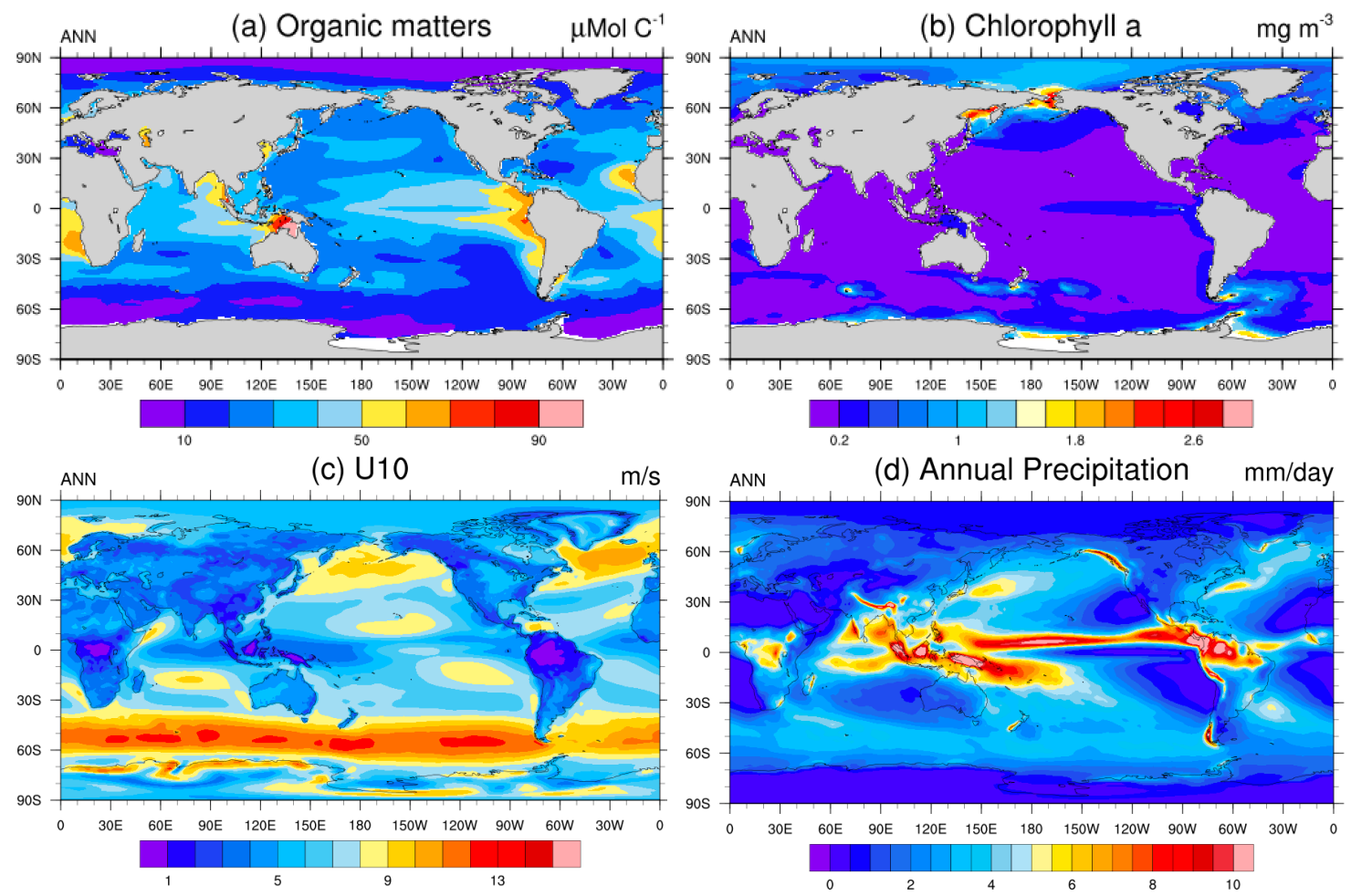

(e) Fine SSA Surface flux $\mu \mathrm{g} \mathrm{m}^{-2} \mathrm{~s}^{-1}$ (f) Coarse SSA Surface flux $\mu \mathrm{g} \mathrm{m}^{-2} \mathrm{~s}^{-1}$
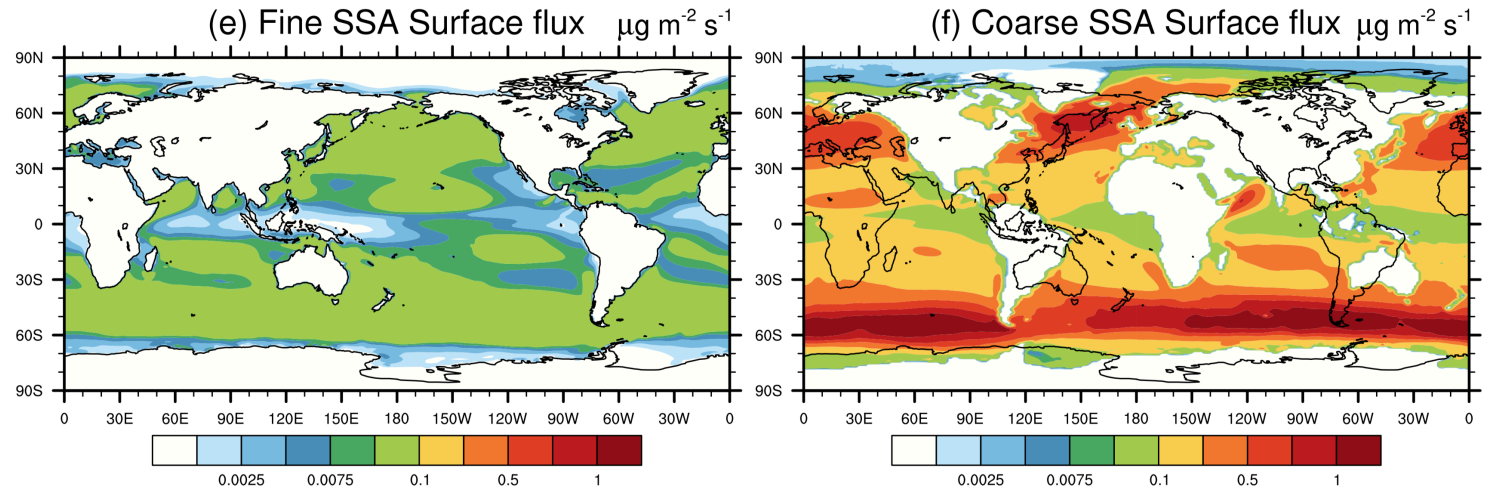

Figure S1. Spatial distributions of (a) ocean organic matter concentration, (b) ocean Chl-a concentration, (c) 10-meter wind speed, (d) annual precipitation, (e) fine mode SSA surface flux, and (f) Coarse mode SSA surface flux. 

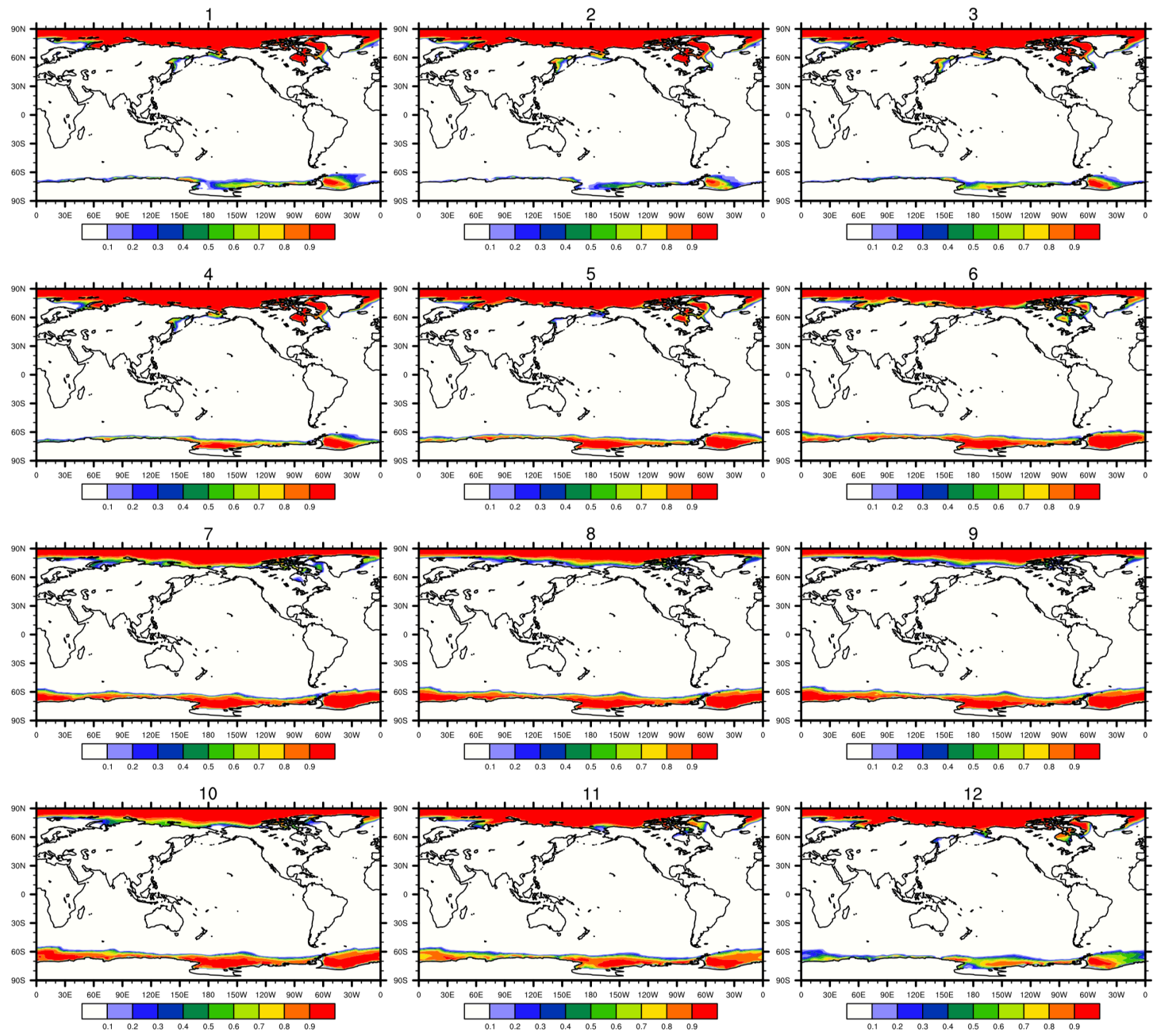

Figure S2. Seasonal variation of global sea ice extent, shown as sea ice fraction in 12 months. 